\title{
Gestión Ambiental de la Fiscalía Provincial en Ecuador. Una Mirada desde la Constitución Ecuatoriana
}

\author{
Environmental Management of the Provincial Prosecutor's Office in \\ Ecuador. A look from the Ecuadorian Constitution
}

\section{Sonia Margarita Barcia Rodríguez}

\section{RESUMEN}

Ante lo retórico de conferir a la naturaleza constitucionalmente el carácter de "sujeto de derechos", sin nadie que vele por sus intereses, el propósito de la investigación fue proponer directrices para que se legisle respecto del otorgamiento a la Fiscalía de facultades para que promuevan los procesos penales y civiles ambientales, cuando se afecte al ambiente o naturaleza, el cual además de ser un bien común a todos las personas, se la ha considerado como un sujeto de derechos, lo contrario sería poseer normas de mera ostentación pública cuyo resultado ha sido "tener a la naturaleza como sujeto de derechos, sin que nadie la represente". Como basamento teóricodocumental, se revisó la Constitución de la República de Ecuador (Asamblea Constituyente, 2008) y la Constitución de la República Federativa de Brasil (Asamblea Nacional Constituyente, 1988). Metodológicamente la investigación siguió una modalidad dogmática-documental y de campo; de este modo, se trabajó con bibliografía y lincografías, complementando los datos con la obtención y recolección de información por parte de los profesionales de libre ejercicio del Cantón de Manabí vinculados con las acciones de la fiscalía encuestados. Esto permitió comprobar la falta de representación jurídica de la naturaleza como sujeto de derecho en el ordenamiento jurídico ecuatoriano. Entre las conclusiones destaca que pese a que constitucionalmente las materias ambientales son de interés público, no existe la normativa ambiental adecuada de fondo y de forma que evite la degradación persistente de la naturaleza.

Palabras clave: gestión ambiental, facultades fiscales, normativa ambiental

\footnotetext{
* Magister en Gestión Ambiental. Magister en Derecho Penal y Criminología. Especialista en Derecho Penal y Justicia Indígena. Especialista Superior en Derecho Procesal. Abogada de los Tribunales y Juzgados del Ecuador. Licenciada en Ciencias Políticas y Sociales.Docente de la Universidad Laica Eloy Alfaro de Manabí Facultad de Derecho. Manabí, Ecuador. Correo Electrónico:sonia_barciap@hotmail.com
} 
Gestión Ambiental de la Fiscalía Provincial en Ecuador. Una Mirada desde la Constitución Ecuatoriana

RECIBIDO: Enero 2018 ACEPTADO: Abril 2018

\begin{abstract}
Given the rhetoric of constitutionally conferring on nature the status of "subject of rights", with no one to watch over their interests, the purpose of the investigation was to propose procedures for legislation regarding the granting of powers to the Prosecutor's Office in order to promote criminal and civil environmental processes, when the environment or nature is affected, which, in addition to being a common good for all people, has been considered as a subject of rights, otherwise there would exist rules of mere public ostentation whose result has been "to think of nature as a subject of rights, without anyone representing it". As a theoretical-documentary basis, the Constitution of the Republic of Ecuador (Constituent Assembly, 2008) and the Constitution of the Federative Republic of Brazil (National Constituent Assembly, 1988) were revised. Methodologically, the research followed a dogmatic-documentary and field modality; in this way, bibliography and lincographies were used, complementing the data while obtaining and gathering information by the freelance professionals of the Canton of Manabí linked to the actions of the surveyed prosecutors. This allowed verifying the lack of legal representation of nature as a subject of law in the Ecuadorian and field legal system was verified, beginning with obtaining and gathering information from the surveyed professionals in legal matter. Among the conclusions, it stands out that although constitutionally the environmental matters are of public interest, there is no adequate environmental regulation in the background and in a way that avoids the persistent degradation of nature.
\end{abstract}

Keywords: environmental management, fiscal powers,environmental regulations

\title{
Introducción
}

La naturaleza o Pachamama pese a ser un sujeto de derechos, carece de un organismo encargado de velar por sus intereses, lo que significa estar frente a un sujeto de derechos en la más absoluta indefensión, porque no se puede pretender que a la naturaleza la defiendan los particulares, quienes carecen de los medios e infraestructura para interponer acciones, generalmente contra los grandes contaminadores, entre ellos, el propio Estado, como ocurre en los municipios vertedores de sus aguas servidas y sin purificar a los cauces naturales de aguas que riegan los alimentos, generando no sólo problemas ambientales con los cuales se 
afecta a la naturaleza, sino también, problemas de salubridad pública, perturbando de esta manera la vida e integridad de las personas.

Ante lo retórico de conferir a la naturaleza el carácter de "sujeto de derechos", sin nadie que vele por sus intereses, el propósito de proponer algunas directrices para que se legisle respecto del otorgamiento a la Fiscalía de facultades promotoras de los procesos penales y civiles ambientales, como ocurre en Brasil, de acuerdo con lo expresado en su carta magna (Constitución de la República Federativa de Brasil, Asamblea Nacional Constituyente, 1988), cuando se afecta al ambiente o naturaleza, la cual además de ser un bien común para todos las personas, ha sido considerada como un sujeto de derechos. Lo contrario sería poseer normas de mera ostentación pública cuyo resultado se resume en "tener a la naturaleza como sujeto de derechos, sin que nadie la represente".

En consecuencia, siendo los intereses ambientales intereses públicos, queda en evidencia una omisión estatal sobre la materia, siendo importante que sea la Fiscalía quien actúe para asegurar una actuación más eficaz en relación con la protección ambiental, lo que ayudará a garantizar un mayor contacto entre la sociedad civil y este organismo, al cual deberá otorgársele la calidad de representante activo en la protección del derecho a vivir en un medio ambiente sano y libre de contaminación, de acuerdo con el actual Estado Constitucional de Derechos y Justicia.

El inciso $2^{\circ}$ del Art. 10 de la Constitución de la República Ecuatoriana (Asamblea Constituyente, 2008) otorga a la naturaleza la calidad de sujeto de derechos, lo que implica conferirle la titularidad de todos los derechos constitucionales que le son pertinentes, pero siendo la naturaleza un bien común a todas las personas e inmaterial, carece de las facultades de defenderse a sí misma, existiendo un vacío legal al no designarse un organismo estatal que vele por sus intereses.

Como se extrae del aporte de Paredes (2017), en la Provincia de Manabí, son varias las entidades públicas y privadas que constituyen fuentes primarias de 
Gestión Ambiental de la Fiscalía Provincial en Ecuador. Una Mirada desde la Constitución Ecuatoriana

contaminación, y por lo tanto, responsables del deterioro de la naturaleza y del consecuente derecho de todas las personas a vivir en un ambiente sano y libre de contaminación, no existiendo ningún organismo que vele por este deterioro, a pesar de las normas de carácter ambiental dictadas por el Ministerio del Ambiente y las autoridades cantonales.

Referente al Cantón Manta, son innumerables los daños al ambiente causados por los vertidos de aguas servidas, de residuos contaminantes de la industria pesquera, de un vertedero municipal que no cumple con las normas mínimas que la ley y la tecnología requieren, generando todo ello un deterioro al buen vivir de los habitantes del Cantón y a las personas que por razones turísticas visitan la ciudad y sus atractivos turísticos, no existiendo organismo alguno que prevenga y sancione los daños provocados.

Como consecuencia de esta situación, se dio paso a un proceso investigativo que permitió aprehender algunos detalles relacionados con esta panorámica, posibilitando percibir la situación actual de la misma al comparar la información de algunos documentos clave y al analizar las respuestas de los profesionales vinculados con la acción de la fiscalía.

\section{Papel de la Fiscalía Ecuatoriana}

Contando con el derecho constitucional y humano de vivir en un ambiente sano, se desconoce por qué a la Fiscalía General del Estado no se le ha dotado constitucionalmente de facultades para proteger el medio ambiente, como sucede por ejemplo con el Ministerio Público de Brasil, el cual desempeña el papel de tutor del medio ambiente, desarrollando actividades en tres ámbitos del derecho: el administrativo, el civil y el penal (Pérez, 2010).

Con una Fiscalía que vele integralmente por los intereses ambientales de la naturaleza se podría dar cumplimiento a los objetivos del Plan del Buen Vivir 2013 2017 (Secretaría Nacional de Planificación y Desarrollo de Ecuador, SENPLADES, 
2013), especialmente con su objetivo $\mathrm{N}^{\circ}$ 7, que tiene como fin "Garantizar los derechos de la naturaleza y promover la sostenibilidad ambiental territorial y global". Por las razones anteriores, la propia Constitución de la República (Asamblea Constituyente, 2008), posee varios instrumentos que velan por el derecho humano a vivir en un ambiente sano, en donde a la naturaleza se le ha conferido, de acuerdo al inciso $2^{\circ}$ del Art. 10 de dicho cuerpo constitucional, el carácter de sujeto de derechos.

De no ser así, todas las normas que establecen el derecho a vivir en un ambiente sano, pueden contravenir esos objetivos y los contemplados por la constitución, dejando sin utilidad práctica los instrumentos existentes en la carta magna para garantizar el derecho a la convivencia en un ambiente sano, impidiendo, en consecuencia, satisfacer los planteamientos detallados en forma expresa en ese Plan del Buen Vivir 2013 - 2017 (SENPLADES, 2013).

Las políticas constitucionales y del "Buen Vivir", priorizan un ambiente sano y privilegian a la persona humana sobre el capital, por tanto, la planificación de las políticas están absolutamente delineadas en esa dirección de acuerdo, lo contrario atentaría contra el derecho humano a vivir en un ambiente sano y sería susceptible de una acción de protección interpuesta por cualquier persona.

\section{Sobre la Gestión y el Interés Público Ambiental}

Respecto al concepto y nociones de medio ambiente, cabe resaltar el aporte de Passos de Freitas y Almeida (2001, p.17), cuando expresa que

Laexpresiónmedioambiente(milieuambiance)fueutilizadaporprimera vez por el naturalistafrancésGeoffreyde Saint-Hilaireen suobraÉtudes progressivesd'unnaturaliste(Estudios progresivos de un naturalista),de1835, d ondemilieusignificaellugardondeestá ose desarrollaunservivo,yambianceque designa loquerodeaeseser. Hay una gran discusiónen cuanto aredundancia del término "medio ambiente", porcontenerdospalabras consignificados similares.

Mientras que se adopta la definición de gestión ambiental de Sánchez y Gándara (2011, p.137), según la cual es el "conjunto de acciones que buscan orientar 
Gestión Ambiental de la Fiscalía Provincial en Ecuador. Una Mirada desde la Constitución Ecuatoriana

y alentar cambiar en las actividades sociales y económicas, como productores y consumidores, para transitar hacia un desarrollo sustentable". Agregando en relación a la gestión pública ambiental que ésta constituye un "mecanismo mediante el cual la sociedad ha impuesto nuevos deberes a los gobiernos conformando una gestión pública ambiental que descansa en tres soportes básicos: la política, el derecho y la administración ambientales".

Por su parte, el interés público ambiental está contenido en la Conferencia de las Naciones Unidas sobre el Medio Humano, también conocida como Primera Cumbre de la Tierra, efectuada en la ciudad de Estocolmo, Suecia, los días 5 al 16 de junio de 1972 (Organización de las Naciones Unidas, 1972, p.72), que marcó el inicio de la redacción de artículos constitucionales relacionados con los intereses públicos ambientales y el derecho al ambiente sano y en la cual se proclamó:

El hombre tiene el derecho fundamental a la libertad, la igualdady el disfrute de condiciones de vida adecuadas en un medio de calidad tal que le permita llevaruna vida digna y gozar de bienestar, y tiene la solemne obligación de proteger y mejorar elmedio para las generaciones presentes y futuras.

Adaptando las características generales del interés público manifestadas por Correa (2006), cabe señalar que éste tiene como finalidad el bien común y debe contribuir a la realización de la dignidad humana en la escala más amplia posible. Miles de años han pasado y el bien común tiene los mismos rasgos que, en su momento expusieron los grandes filósofos Platón y Aristóteles.

En efecto, Guerra (2005, p.1), citando a Platón en su obra "La República", señala que éste concebía al bien común "como un bien que trasciende los bienes particulares ya que la felicidad de la ciudad debe ser superior y hasta cierto punto independiente de la felicidad de los individuos". Agregando a esta cita que Aristóteles perfeccionó la idea de "bien común", en su obra "La Política", cuando expresa que"el fin de la ciudad es el vivir bien (...) Hay que suponer, en consecuencia, que la comunidad política tiene por objeto las buenas acciones y no sólo la vida en común". 
En concordancia con lo anterior, el bien común tiene estrecha relación con el "buen vivir" o "sumak kawsay", concepto expresado por Larrea (2011, p.60), cuando expresa:

En la Constitución del Ecuador se supera la visión reduccionista del desarrollo como crecimiento económico y se establece una nueva visión en la que el centro del desarrollo es el ser humano y el objetivo final es el alcanzar el sumak kawsay o Buen Vivir. Frente a la falsa dicotomía entre Estado y mercado, impulsada por el pensamiento neoliberal, la Constitución ecuatoriana formula una relación entre Estado, mercado, sociedad y naturaleza. El mercado deja de ser el motor que impulsa el desarrollo y comparte una serie de interacciones con el Estado, la sociedad y la naturaleza. Por primera vez, en la historia de la humanidad una Constitución reconoce los derechos de la naturaleza y ésta pasa a ser uno de los elementos constitutivos del Buen Vivir.

De acuerdo con lo expuesto, teóricamente se esboza una retórica sobre el "buen vivir", a la naturaleza o Pachamama a la que se considera sujeto de derechos y los deberes del Estado del numeral $1^{\circ}$ del Art. 277 de la Constitución de la República del Ecuador (Asamblea Constituyente, 2008) en el cual "El Estado se obliga para la consecución del buen vivir a garantizar los derechos de las personas, las colectividades y la naturaleza", puede apreciarse que se está frente a normas que precisan de una complementación normativa para su efectivo cumplimiento como gestión o cuidado ambiental, de lo contrario van a carecer de la eficacia que la urgencia de proteger el ambiente requiere, siendo dichas normas, por ahora, normas de mera ostentación pública, sin ningún sustento normativo que permita la justiciabilidad de los derechos de conformidad al inciso final del numeral $3^{\circ}$ del Art. 11 de la Constitución de la República.

El Art. 14 y el numeral 27 del Art. 66 de la Constitución de la República del Ecuador (Asamblea Constituyente, 2008) reconocen el derecho de la población a vivir en un ambiente sano y ecológicamente equilibrado, que garantice la sostenibilidad y el buen vivir, sumak kawsaw. El hecho de vivir en un ambiente sano establecido en 
Gestión Ambiental de la Fiscalía Provincial en Ecuador. Una Mirada desde la Constitución Ecuatoriana

nuestra Constitución es absolutamente "antropocéntrico", el numeral 27 del Art. 66 ibídem garantiza a las personas el derecho a vivir en un ambiente sano, ecológicamente equilibrado y en armonía con la naturaleza, lo que obedece a un concepto obsoleto y parcial indigno de un país que cuenta con la mayor biodiversidad del planeta.

En relación con los principios democráticos y la convivencia pluralista, debe tenerse en consideración un Estado Constitucional de Derechos y Justicia. Destacable es señalar que el Art. $1^{\circ}$ de la Constitución de la República del Ecuador (Asamblea Constituyente, 2008) señala en su primera parte que «El Ecuador es un Estado constitucional de derechos y justicia...", dándose a entender con el "estado de derechos" que en él priman los derechos de la persona humana, concordando ello con la correcta aplicación de las normas positivas, ya que la justicia, al orientar teleológicamente a estos derechos debe tener por objeto perseguir la reducción de situaciones de injusticia y dentro de ello está violentar el derecho a vivir en un ambiente sano y libre de contaminación.

De igual modo, el concepto de interés público ambiental comprende los procesos de decisión que corresponden a las instituciones políticas y administrativas del Estado y los procesos de selección a los sistemas institucionales restantes, como son los jurisdiccionales y la actividadpropia de las entidades fiscalizadoras superiores relacionadas con los aspectos preventivos y represivos ambientales, a fin de evitar los daños al ambiente, destacando que se carece de la infraestructura necesaria para velar integralmente por la protección de los derechos ambientales.

\section{Derecho Comparado: El Interés Público Ambiental en Brasil}

El Art. 5, fracción LXXIII, de la Constitución de la República Federativa de Brasil (Asamblea Nacional Constituyente, 1988), dispone que:

Cualquier ciudadanoes parte legítima para proponer la acción popular que pretendaanular un acto lesivo para el patrimonio público o de unaentidad en que el Estado participe, para la moralidadadministrativa, 
para el medio ambiente o para el patrimoniohistórico y cultural, quedando el actor, salvo mala fecomprobada, exento de las costas judiciales y de los gastos.

En la protección de los intereses públicos ambientales, la República de Brasil claramente contempla en su Constitución la acción popular que puede ser interpuesta por cualquier persona en lo relacionado, entre otros, con los intereses ambientales, estando exenta absolutamente de cosas judiciales y gastos, entendiéndose, a la acción, según expresa Cappeletti (1978, p.337) como un "derecho humano a la justicia".

Pese a lo amplia de la disposición constitucional, la República del Brasil, no solo se conformó en dejar la tutela del interés público ambiental a las acciones de los particulares. Siendo uno de los países que presenta mayores avances en la materia, la acción de intervención del Ministerio Público en la defensa del interés público ambiental queda justificada jurídicamente en las palabras de Pérez (2010, pp. 1-2):

El Brasil, teniendo en consideración que una porción considerable de su sociedad aún no dispone de condiciones para la defensa individual de los derechos asegurados por la Constitución, dentro de los cuales están los relativos a la preservación ambiental, atribuye el encargo de la tutela de estos derechos, ante la Justicia, al Ministerio Público, institución independiente de los tres otros poderes, que actúa en nombre del pueblo y en el interés público. Así, el Ministerio Público, en los términos contenidos en el Art. 127 de la Constitución de la República, promulgada el 05/10/1988, es considerado una institución permanente, esencial a la función jurisdiccional del Estado, incumbiéndole la defensa del orden jurídico, del régimen democrático y de los intereses sociales e individuales indisponibles.

Pérez (2010) retoma la Ley $\mathrm{N}^{\circ} 7.347 / 85$, con la cual se percibe la posibilidad de una intervención por parte del Ministerio Público Federal o de los Estados, al otorgarles facultades procesales para emprender acciones civiles. De esta manera se abre una ventana a las sanciones de aquellos que provoquen daños ambientales y se coloca a Brasil como precursor en la 
Gestión Ambiental de la Fiscalía Provincial en Ecuador. Una Mirada desde la Constitución Ecuatoriana

delegación de nuevas funciones al citado Ministerio Público. Así se constituye en un ente más capacitado para velar por la tutela de los intereses del orden civil, sean estos difusos o colectivos.

En resumen, puede afirmarse que el papel del Ministerio Público del Brasil es pionero en materia ambiental, siendo la Constitución de la República Federativa de Brasil (Asamblea Nacional Constituyente, 1988), la que estableció en su Art. 225 varios incisos en los cuales se refiere a la defensa del ambiente, definiéndolo como:

...bien de uso común del pueblo y esencial para la sana calidad de vida, incumbiéndole al poder público y a las personas la preservación del medio ambiente, destacando que en la misma disposición constitucional se comprende el derecho a la reparación del daño ambiental, así como la aplicación de sanciones penales y administrativas a quienes causaren perjuicios al ambiente.

La acción civil pública brasileña surgió con la Ley $N^{\circ} 7.347$ de Acción Civil Pública de 24/07/1985 (citada por Pérez, 2010 y Medeiros, 2012), en la cual se establecen las normas y el procedimiento tendientes a sancionar a los responsables por daños al medio ambiente, al consumidor, a los bienes y derechos de valor artístico, estético, histórico, turístico y paisajístico, que son considerados intereses públicos. Al respecto, Medeiros (2012, pp.30 y 33) expresa sobre la acción civil pública que

La Ley $\mathrm{N}^{\circ} 7.437 / 85$ hizo posible una innovación en el clásico proceso civil, por sus características instrumentales, cooperando de forma considerable con nuestro ordenamiento jurídico. La acción civil pública es una ley infra constitucional, que busca la protección, prevención o composición de los daños morales o patrimoniales causados al medio ambiente, a los consumidores, a los bienes y derechos de valor artístico, histórico, turístico y paisajístico y a cualquier otro interés difuso o colectivo [...] El objeto de la acción civil pública ambiental es garantizar un medio ambiente ecológicamente equilibrado, para las presentes y futuras generaciones, la acción civil pública tiene como objeto inmediato el cumplimiento de la obligación de hacer o no hacer o la condena pecuniaria, aun cuando el legislador no admitió la obligación de hacer o no hacer con la indemnización en dinero, entendiéndose que 
delante de las particularidades de cada caso, es posible la condena acumulativa, en base al principio de reparación integral del daño.

Consecuente con lo expuesto anteriormente, Medeiros (2012) retoma el Art. 5 de la Ley de Acción Civil Pública de 24/07/1985, enfatizando que éste establece en forma categórica que "La acción principal y la cautelar podrán ser propuestas por el Ministerio Público, por la Unión, por los Estados y Municipios. Podrá también ser propuesta por autarquías, empresas públicas, fundaciones, sociedades de economía mixta o por asociación...". Lo fundamental de la legislación transcrita, según Medeiros (2012, pp. 30 y 33), es que

Están habilitados para tutelar el medio ambiente, todos los legitimados por la ley, que lo pueden hacer conjunta o separadamente. Por eso, en el contexto de la Ley 7.347/85 la legitimación es concurrente o disyuntiva [...] Cualquier persona podrá provocar la iniciativa del Ministerio Público, entregándole la información necesaria, en el caso que se verifique lesión o amenaza de lesión al medio ambiente ecológicamente equilibrado.

Esta defensa de los intereses ambientales en Brasil, se sustenta en el derecho humano a vivir en un ambiente sano, que constituye el medio en donde se desenvuelve normalmente la vida, razón por la cual, cualquier alteración o daño al ambiente, pone en peligro no sólo la vida humana, sino la de todo ser viviente, por este motivo en Brasil se instauró esta acción para la existencia de un ambiente de calidad que asegure la vida de todo ser viviente.

\section{Legitimación Activa de la Fiscalía para la Acción Ambiental en Ecuador}

Naciendo de los delitos ambientales la acción penal pública y teniendo el o la fiscal el monopolio del ejercicio de esta acción, obviamente que, de conformidad al inciso $2^{\circ}$ del Art. 410 del Código Orgánico Integral Penal Asamblea Nacional de la República del Ecuador, 2014), a estos corresponde el ejercicio de la acción penal pública sin necesidad de denuncia previa. En efecto, de conformidad con el Art. 411 
Gestión Ambiental de la Fiscalía Provincial en Ecuador. Una Mirada desde la Constitución Ecuatoriana

del mismo cuerpo legal, la Fiscalía ejercerá la acción penal pública cuando tenga la convicción suficiente de la infracción y de la responsabilidad de la persona procesada, pudiendo abstenerse de ejercer la acción penal en virtud del principio de responsabilidad.

En el caso de los daños al medio ambiente puede ocurrir que se trate de accidentes fortuitos que verdaderamente causen perjuicios al ambiente, pero si estos daños se los aprecia con un criterio penal, en virtud del principio de oportunidad quedarán los hechos en la más absoluta impunidad, cosa que no ocurre en el derecho comparado, como en Brasil, en donde los fiscales cuentan con una acción civil que da lugar a una investigación civil que permite sancionar a quienes causen daños al medio ambiente.

En virtud de este procedimiento, cabe destacar que al medio ambiente no se le ha otorgado la calidad de sujeto de derechos en Brasil, como si ocurre en Ecuador; también se debe resaltar que según las estadísticas de ingreso las causas ambientales son ínfimas, no queriendo significar esto la inexistencia de daños ambientales.

\section{Metodología}

La investigación siguió los preceptos de Duverger (1971), Pizzorrusso (1987), Villaseñor y Gómez (2013), que la caracterizan como una modalidad dogmáticadocumental, por trabajar con bibliografía y lincografías; jurídica-sociológica, con la cual se revisó la Constitución Ecuatoriana y comprobó la falta de representación jurídica de la naturaleza como sujeto de derecho en el ordenamiento jurídico ecuatoriano y de campo, a partir de la obtención y recolección de información por parte de 99 comunicadores sociales y profesionales del Derecho en libre ejercicio del Cantón de Manta, Provincia de Manabí, relacionados con una participación activa de las y los fiscales en la defensa del interés público ambiental que fueron encuestados.

Tipológicamente, es un trabajo jurídico exploratorio que permitió conocer la magnitud del fenómeno investigado tanto en los documentos, como en el campo, 


\section{Sonia Margarita Barcia Rodríguez.}

Telos Vol. 20, No. 2 (2018). 307-329

donde quedó demostrado que la naturaleza, pese a ser constitucionalmente un sujeto de derecho en este país y ser los intereses ambientales de carácter público, carece de la adecuada protección por parte de un Estado Constitucional de Derechos y Justicia en el cual uno de sus deberes primordiales (Art. $3 \mathrm{~N}^{\circ} 7$ de la Constitución de la República de Ecuador, Asamblea Constituyente, 2008) es proteger el patrimonio natural del Ecuador.

En tanto, el procesamiento y análisis de la información, se realizó a través del uso de fichas bibliográficas en las cuales se recogió información de los libros consultados y directamente relacionados con el tema, así como, fichas lincográficas obtenidas de las visitas a páginas electrónicas especiales relacionadas con el tema investigado, lo que se complementó con una investigación de campo, para complementar los datos encontrados a nivel documental. Las técnicas de recolección de la información seleccionadas fueron encuestas y estadísticas, con ellas se efectuó el correspondiente recuento de las opiniones de los encuestados, comparando las cifras existentes y analizando las tendencias reflejadas frente a esta problemática.

Respecto a la recolección de información, las técnicas de investigación empleadas en el tema de este trabajo fueron mixtas, gracias a las cuales se pudieron alcanzar los objetivos generales y específicos, sin las cuales, la metodología aplicada no habría sido posible materializarla, para lo cual fueron vitales las fichas bibliográficas (por su versatilidad, se ha utilizado esta técnica atendiendo que la materia a investigar necesariamente se encuentra en gran medida en la doctrina, legalización y jurisprudencia tanto nacional como comparada), lincográficas (se indagó en los buscadores jurídicos de internet sobre el tema) y de campo (se transcribieron las respuestas de las personas encuestadas).

En este sentido, se diseñó un instrumento de recolección de datos, bajo el formato de encuestas, que complementara la revisión documental realizada. El cuestionario fue cerrado y contentivo de siete preguntas clave para dilucidar su opinión referente a la temática investigada. De esta manera, se contactaron 99 
Gestión Ambiental de la Fiscalía Provincial en Ecuador. Una Mirada desde la Constitución Ecuatoriana

profesionales de libre ejercicio del Cantón de Manta, Provincia de Manabí vinculados con las acciones de la fiscalía, lo cual constituyó un censo poblacional.

El procesamiento de la información: para comprender el estado de la legislación acerca de la protección del interés público ambiental, se analizó la situación existente en el derecho comparado, especialmente con Brasil, donde las Fiscalías cumplen un papel preponderante en la protección de la naturaleza, especialmente desde los puntos de vista preventivos, sancionatorios, de restauración e indemnizatorios.

\section{Resultados}

A continuación se presentan los resultados de la encuesta realizada a los 99 profesionales vinculados con las acciones de la fiscalía, los cuales se expresan en tablas donde se muestran las frecuencias absolutas y relativas con su respectivo análisis e interpretación de la investigadora como mecanismo de expresar la coincidencia con los aportes teórico-jurídicos bajo los cuales se soportó la investigación.

Tabla 1. Adecuación de las facultades de los fiscales para velar por el interés público ambiental

\begin{tabular}{|c|c|c|}
\hline Alternativas & Frecuencia & $\%$ \\
\hline $\begin{array}{l}\text { 1. No pueden tratarse las materias ambientales de la misma } \\
\text { forma que los delitos comunes }\end{array}$ & 32 & 32.3 \\
\hline $\begin{array}{l}\text { 2. Hay que otorgarles un papel más protagónico no solo en } \\
\text { materia penal, sino también en la persecución de la reparación } \\
\text { civil del daño ambiental }\end{array}$ & 57 & 57.6 \\
\hline 3. No contesta & 10 & 10.1 \\
\hline Total & 99 & 100 \\
\hline
\end{tabular}

Fuente: Elaboración propia

Como se observa en la Tabla 1, los encuestados manifestaron en un $57.6 \%$ que a las y los fiscales debe otorgárseles un papel más protagónico en la defensa del 
derecho a vivir en un ambiente sano, porque de conformidad al inciso $2^{\circ}$ del Art. 10 de la Constitución de la República de Ecuador (Asamblea Constituyente, 2008) a la naturaleza se la considera un sujeto de derechos y resulta inconveniente que sean los particulares los que deban interponer acciones para su protección, ya que de conformidad al inciso final del Art. 400 del mismo cuerpo constitucional, se declara de interés público la conservación de la biodiversidad y todos sus componentes, razón por la cual para proteger este interés deberían otorgarse facultades especiales a las y los fiscales en esta materia, cosa que ocurre en el derecho comparado.

En tanto $32.3 \%$ señaló que los delitos ambientales no se pueden tratar como delitos comunes, porque es la naturaleza la que resulta afectada con los ilícitos y ésta, conforme al inciso $2^{\circ}$ del Art. 10 de la Constitución de la República de Ecuador (Asamblea Constituyente, 2008) tiene el carácter de sujeto de derecho; finalmente, $10.1 \%$ de los encuestados no respondió la pregunta.

Los delitos ambientales deben tratarse de manera especial porque el sujeto pasivo es la naturaleza, la cual carece de representantes legales, no siendo adecuado que esta representación quede entregada a la buena voluntad de los particulares. Por esta razón un importante sector señaló que a los fiscales se les debería otorgar competencias ambientales para perseguir los delitos ambientales en forma amplia, incluyéndose con ello la restauración del daño causado.

Se comprende así cómo los delitos ambientales no pueden tratarse como delitos comunes, pues el afectado es un sujeto de derecho, como la naturaleza, diferente a la persona humana y, además, el bien jurídico protegido está constituído por intereses difusos pertenecientes a todos, destacando que siendo la biodiversidad materia de interés público ambiental, la naturaleza también debe ser adecuadamente representada. 
Gestión Ambiental de la Fiscalía Provincial en Ecuador. Una Mirada desde la Constitución Ecuatoriana

Tabla 2. Efectividad o retórica de la norma del inciso $2^{\circ}$ del Art. 10 de la Constitución de la República que señala que la naturaleza es un sujeto al que debe reconocérsele los derechos

\begin{tabular}{|c|c|c|}
\hline Alternativas & Frecuencia & $\%$ \\
\hline 1. Es deficiente & 7 & 7.1 \\
\hline $\begin{array}{l}\text { 2. Es absolutamente retórica porque la naturaleza carece de un } \\
\text { representante que la defienda, lo que hace incluso la norma }\end{array}$ & 92 & 92.9 \\
\hline 3. No contesta & 0 & 0.0 \\
\hline Total & 99 & 100 \\
\hline
\end{tabular}

\section{Fuente: Elaboración propia}

De acuerdo con la Tabla 2, los entrevistados manifestaron en un $7.1 \%$ que se trata de una norma deficiente y un $92.93 \%$ optó por señalar que esta norma es absolutamente retórica porque la naturaleza carecede un representante que la defienda, lo que hace ilusoria la misma, razón por la cual existe acuerdo en los encuestados de tener una percepción negativa acerca de la eficacia de esta normativa.

Como se expuso en el análisis, no se puede ser sujeto de derecho sin que exista para éste un representante legal, lo que deja a este sujeto en la más absoluta indefensión contraviniendo las normas constitucionales que establecen que es deber primordial del Estado proteger el patrimonio natural del país. El inciso $2^{\circ}$ del Art. 10 de la Constitución de la República Ecuatoriana (Asamblea Constituyente, 2008) confiere a la naturaleza la calidad de sujeto de derechos, de cumplirse este precepto, debería contar con todos los derechos constitucionales involucrados, pero dado su carácter de bien común a todas las personas e inmaterial, esto no se cumple, comprendiendo los encuestados que existe un vacío legal al no designarse un organismo estatal que vele por sus intereses. 
Tabla 3. Adecuación de someter a procesos civiles ordinarios las indemnizaciones en materia ambiental

\begin{tabular}{|c|c|c|}
\hline Alternativas & Frecuencia & $\%$ \\
\hline 1. No & 94 & 94.9 \\
\hline 2. $\mathrm{Si}$ & 5 & 5.1 \\
\hline Total & 99 & 100 \\
\hline
\end{tabular}

Fuente: Elaboración propia

Los entrevistados manifestaron en un $94.9 \%$ que por la urgencia de las materias ambientales, las indemnizaciones no deben someterse a dilatados procesos civiles ordinarios, solo un $5.1 \%$ declaró que el procedimiento ordinario es adecuado. La pregunta se responde por sí sola porque debido a la urgencia de las materias ambientales, es necesario un procedimiento sumario para cobrar las indemnizaciones que correspondan.

En este sentido, se comparte lo manifestado por el 95\% de los encuestados, ya que estas materias merecen ser tratadas preferentemente porque hay un interés público comprometido, no existiendo un título específico al respecto en el nuevo Código General de Procesos que aún no entra en vigencia.

Tabla 4. Necesidad de modificar juicio ordinario o establecer procedimiento especial para dar celeridad a la acción civil

\begin{tabular}{|c|c|c|}
\hline \multicolumn{1}{|c|}{ Alternativas } & Frecuencia & \% \\
\hline $\begin{array}{l}\text { 1. Debe abreviarse el juicio ordinario o someterse estos } \\
\text { Asuntos a juicio verbal sumario }\end{array}$ & 7 & 7.1 \\
\hline $\begin{array}{l}\text { 2. Es necesario un procedimiento especial por la urgencia } \\
\text { que ameritan los asuntos ambientales }\end{array}$ & 92 & 92.9 \\
\hline Total & 99 & 100 \\
\hline
\end{tabular}

Fuente: Elaboración propia

Conforme expresa la Tabla 4, la mayoría de los abogados encuestados se manifestó a favor de hacer modificaciones. Mientras $7.1 \%$ expuso la necesidad de abreviar el juicio ordinario, $92.9 \%$ señaló que era adecuado un nuevo procedimiento especial, más breve. Como se percibe, existe una percepción mayoritaria de modificar 
Gestión Ambiental de la Fiscalía Provincial en Ecuador. Una Mirada desde la Constitución Ecuatoriana

el actual procedimiento ordinario tendiente a hacer más célere la tramitación de una acción indemnizatoria. Se coincide con lo señalado, en cuanto a la modificación del procedimiento y, en especial, por la existencia de un procedimiento especial más breve.

Tabla 5. Otorgamiento a los fiscales de un papel activo y protagónico para velar integralmente por el derecho a vivir en un ambiente libre de contaminación

\begin{tabular}{|c|c|c|}
\hline Alternativas & Frecuencia & $\%$ \\
\hline 1. No & 0 & 0.0 \\
\hline 2. $\mathrm{Si}$ & 99 & 100 \\
\hline Total & 99 & 100 \\
\hline
\end{tabular}

Fuente: Elaboración propia

En concordancia con los resultados de las tablas anteriores, en ésta se muestra que por las razones expuestas anteriormente, la unanimidad de los entrevistados señaló que es absolutamente conveniente otorgar a los fiscales facultades amplias para que velen integralmente por la protección ambiental. De esta manera, queda en evidencia la necesidad de que los intereses públicos ambientales pueden ser protegidos otorgando mayores competencias a las y los fiscales. No existe inconveniente alguno para dar a los fiscales un papel activo y protagónico para velar integralmente por el derecho a vivir en un ambiente libre de contaminación.

Tabla 6. Interés de los particulares en acciones para la defensa de los intereses ambientales propios, difusos o colectivos

\begin{tabular}{|c|c|c|}
\hline Alternativas & Frecuencia & $\%$ \\
\hline 1. No & 99 & 100 \\
\hline 2. $\mathrm{Si}$ & 0 & 0.0 \\
\hline Total & 99 & 100 \\
\hline
\end{tabular}

Fuente: Elaboración propia

La unanimidad de los encuestados señaló que en el ejercicio de su profesión y revisando los libros de ingreso de las fiscalías, no hay denuncias sobre la materia, lo 
que revela una falta de interés de los particulares por interponer acciones que tengan relación con la protección de los intereses ambientales. Debido a la avenencia de la respuesta, queda en evidencia que los particulares no tienen interés en asumir la representación de la naturaleza para defender las violaciones al derecho a vivir en un ambiente sano, lo que obedece a lo prolongado y costoso que implica para un particular asumir esta defensa.

Tabla 7. Falta de interés de los particulares en presentar acciones penales públicas y civiles ambientales

\begin{tabular}{|c|c|c|}
\hline Alternativas & Frecuencia & \% \\
\hline 1. Desconfianza en la justicia y falta de recursos & 85 & 85.9 \\
\hline $\begin{array}{l}\text { 2. A que los que contaminan son generalmente } \\
\text { empresarios de gran poder económico }\end{array}$ & 10 & 10.1 \\
\hline $\begin{array}{l}\text { 3. A la enorme pérdida de tiempo que implica la } \\
\text { tramitación judicial }\end{array}$ & 4 & 4.0 \\
\hline Total & 99 & 100 \\
\hline
\end{tabular}

\section{Fuente: Elaboración propia}

Como se observa en la Tabla 7, los encuestados seleccionaron diversas opciones que dejaron en evidencia las razones por las cuales los particulares no interponen denuncias ambientales: 85.9\% de ellos manifestó tener desconfianza en la justicia y falta de recursos; $10.1 \%$ señaló que quienes contaminan son generalmente empresarios de gran poder económico contra los cuales es difícil debatir y, finalmente, $4 \%$ respondió que los particulares no denuncian debido a la enorme pérdida de tiempo que implica la tramitación judicial.

La exposición de esta percepción negativa, deja en evidencia la necesidad de que la naturaleza sea representada debidamente, como sujeto de derecho para que se vele adecuadamente por el interés público ambiental; entre las causas por las cuales los particulares no denuncian los delitos ambientales destaca que esta omisión obedece a que los contaminadores, generalmente, se corresponden con grandes 
Gestión Ambiental de la Fiscalía Provincial en Ecuador. Una Mirada desde la Constitución Ecuatoriana

empresas e incluso con los organismos dependientes de la Administración del Estado, y a la carencia de los recursos para solventar un juicio prolongado y de alto costo.

En resumen, los resultados ponen de manifiesto que las y los fiscales del Ecuador carecen de competencia para velar por los intereses públicos ambientales y representar a la naturaleza como sujeto de derecho en la defensa de sus intereses, haciendo perceptible la necesidad de ampliar los poderes de la Fiscalía ecuatoriana en materia de gestión ambiental.

Otorgando a la Fiscalía poderes para prevenir y sancionar los daños ambientales, provengan de donde provengan, se dará a este organismo un papel activo en la defensa de la naturaleza, lo que implicará equipararla a lo que sucede en el derecho comparado, consiguiendo que nuestras fiscalías no se queden, como lo están ahora, anquilosada en el ius puniendi del Estado y alejadas del interés público ambiental, razón por la cual, al carecer la naturaleza de un representante para velar por sus intereses, se deterioran impunemente los communis omnium por parte de los contaminadores del sector tanto público como privado, afectando no solo a las actuales generaciones, sino que también a las futuras.

Esto contraviene los preceptos acordados en la Conferencia de las Naciones Unidas sobre el Medio Humano (Organización de las Naciones Unidas, 1972), que marcó el inicio de la redacción de artículos constitucionales relacionados con los intereses públicos ambientales y el derecho al ambiente. Así como los planteamientos de Sánchez y Gándara (2011), al no cumplirse las acciones que permitan transitar hacia un desarrollo sustentable mediante el resguardo de la naturaleza.

\section{Conclusiones}

La normativa ambiental ecuatoriana es insuficiente para velar adecuadamentepor el derecho a vivir en un ambiente sano, libre de contaminación y ecológicamente equilibrado que garantice la sostenibilidad y el buen vivir. 
Pese a que la naturaleza es considerada un sujeto de derechos que puede ejercer los derechos constitucionales y los consagrados en los instrumentos internacionales, está en la más absoluta indefensión por carecer de un organismo que la represente. Cuando en los delitos ambientales existen daños materiales y no se afecta a las personas, generalmente los fiscales ejercen el principio de oportunidad, quedando en la impunidad quienes atenten contra la naturaleza como bien jurídico protegido.

El procedimiento para ejercer las acciones civiles ambientales es el ordinario, siendo un hecho notorio la lentitud del proceso, que al final implica, prácticamente una denegación de justicia. Pese a que constitucionalmente las materias ambientales son de interés público, no existe la normativa ambiental adecuada de fondo y de forma que evite la degradación persistente de la naturaleza.

Se recomiendaun procedimiento civil con participación de los fiscales a fin de lograr que todo daño a la naturaleza sea reparado adecuadamente como ocurre en el derecho comparado (caso Brasil). Una normativa civil que haga efectiva la responsabilidad objetiva ambiental permitirá hacer efectivo el principio "quien contamina paga" lo que consentirá en restaurar los daños ambientales protegiéndose adecuadamente los derechos de la naturaleza como sujeto de derechos.

Cuando en los delitos ambientales existen daños materiales y no se afecta a las personas, aun cuando los fiscales ejerzan el principio de oportunidad, el procedimiento civil propuesto permitirá hacer efectiva la responsabilidad civil objetiva sin que se atienda al dolo o culpa del agente. El procedimiento civil que se propone debe ser especialísimo y breve a fin de hacer efectiva la restauración ambiental quebrantada por el hecho de terceros con una normativa del procedimiento civil de derecho público y con absoluta concordancia con el interés público ambiental que la Constitución de la República consagra con participación de la Fiscalía, a fin que se cumpla el principio de "quien contamina paga", atendido a que la responsabilidad civil ambiental es de carácter objetivo. 
Gestión Ambiental de la Fiscalía Provincial en Ecuador. Una Mirada desde la Constitución Ecuatoriana

\section{Referencias Bibliográficas}

Asamblea Constituyente (2008). Constitución de la República del Ecuador. Registro Oficial 449 de 20 de octubre de 2008. Ecuador.

Asamblea Nacional Constituyente (1988). Constitución de la República Federativa de

Brasil. Extraído de http://www.wipo.int/edocs/lexdocs/laws/es/br/br117es.pdf consulta: 20/06/15.

Asamblea Nacional de la República del Ecuador (2014). Código Orgánico Integral

Penal (COIP). Registro Oficial Suplemento 180 de 10 de febrero de 2014.

Ecuador.

Cappeletti, Mauro (1978). Justicia Constitucional Supranacional. El control judicial de las leyes y la jurisdicción de las libertades a nivel internacional.Revista de la Facultad de Derecho de México. $N^{\circ}$ 110, mayo-junio México (Pp. 237366).

Correa Fontecilla, Jorge. (2006). Algunas consideraciones sobre el interés público en

la Política y el Derecho. Revista Española de Control Externo. Volumen 8, $\mathrm{N}^{\mathrm{o}}$ 24. España (Pp. 135-164).

Duverger, Maurice (1971). Métodos de las Ciencias Sociales. Editorial Ariel. España.

Guerra López, Rodrigo (2005). Bien común: la maduración de un concepto. Revista

Bien Común. Año XI, No. 128. México (Pp. 15-19).

Larrea Maldonado, Ana María (2011). El Buen Vivir como Hegemonía en la Constitución Ecuatoriana. Revista Utopía y Praxis Latinoamericana. Año 16, $\mathrm{N}^{\mathrm{o}}$ 53. Venezuela (Pp.59-70).

Medeiros Monte Ferreira, Tatianne (2012) Acción civil pública: importante instrumento de tutela del medio ambiente. Editorial Universidad Estadual de Paraíba. Brasil.

Organización de Naciones Unidas (ONU, 1972). Conferencia de las Naciones Unidas sobre el Medio Humano.Extraído de https://www.dipublico.org/conferencias/mediohumano/A-CONF.48-14-

REV.1.pdf consulta: 20/07/15.

Paredes Rivera, Sofía (2017). Residuos industriales, principales contaminantes del Río Muerto. Extraído de https://revistademanabi.com/2017/05/31/residuosindustriales-principales-contaminantes-del-rio-muerto/ consulta: 20/06/17.

Passos de Freitas, Vladimir y Almeida Passos de Freitas, Mariana (2001). Derecho Administrativo y Medio Ambiente. Editorial Juruá. Brasil.

Pérez Greco, Pablo José (2010). El Ministerio Público y La Defensa del Medio Ambiente. ZWARG artículos ambientales. Brasil.

Pizzorrusso, Alejandro (1987). Curso de Derecho Comparado. Editorial Ariel. España.

Sánchez y Gándara, Arturo (2011). Conceptos Básicos de Gestión Ambiental y Desarrollo Sustentable. Editores: Instituto Nacional de Ecología (INE) y Secretaría de Medio Ambiente y Recursos Naturales (SEMARNAT). México. 
Secretaría Nacional de Planificación y Desarrollo de Ecuador (SENPLADES, 2013).Plan nacional para el buen vivir 2013 - 2017. Extraído de http://ftp.eeq.com.ec/upload/informacionPublica/2013/PLAN-NACIONALPARA-EL-BUEN-VIVIR-2013-2017.pdf consulta 26/07/15.

Villaseñor, Isabel y Gómez, Juan (2013). Investigación y Documentación Jurídica. Editorial Dykinson, S.L. España. 